\title{
REVIEW
}
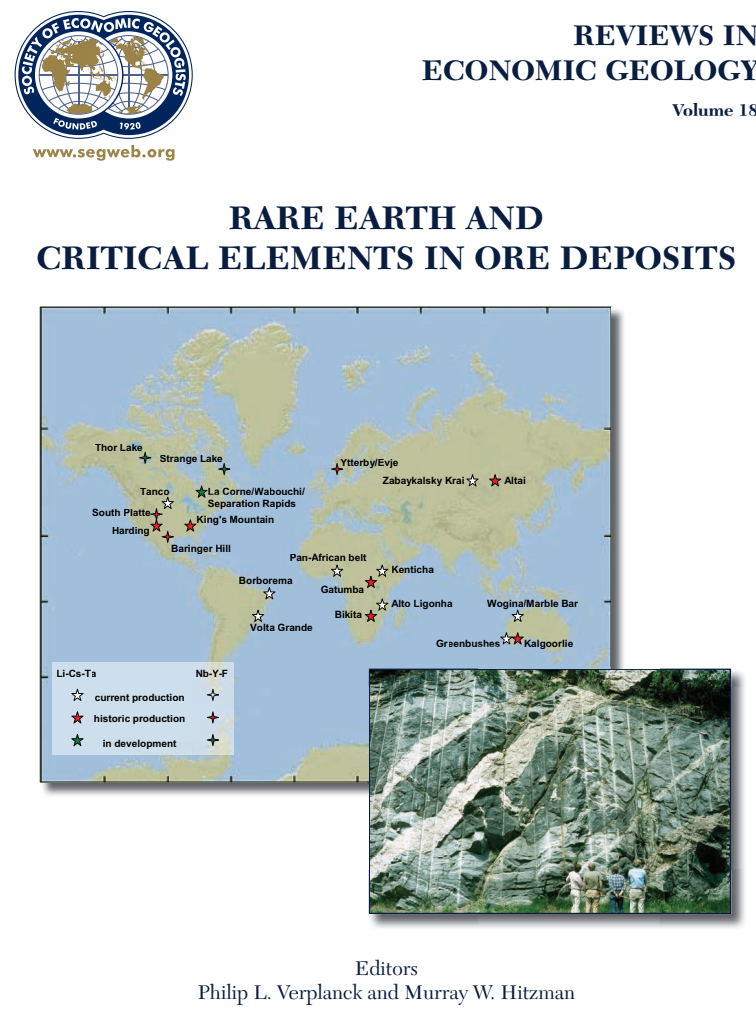

SOCIETY OF ECONOMIC GEOLOGISTS, INC.

\section{Rare Earth and Critical Elements in Ore Deposits}

\section{Philip L. Verplanck and Murray W. Hitzman (editors)}

\author{
REVIEWS IN ECONOMIC GEOLOGY, Volume 18 \\ Publisher: Society of Economic Geologists, Inc. \\ Website: www.segweb.org \\ Published: 2016; 365 p. \\ Orders online: $\$ 135$ (USD); Softcover + CD; other format: PDF \\ SEG member discount through the SEG Bookstore
}

\author{
Reviewed by Andrew Kerr \\ Department of Earth Sciences \\ Memorial University \\ St. John's, Newfoundland and Labrador, A1B 3X5, Canada \\ E-mail:akern@mun.ca
}

It has often been said that the only thing that remains constant in the world of natural resource commodities is change - and this was especially true in the first decades of our new century, which saw sudden and often unpredicted interest in a range of unfamiliar minor commodities. This new Reviews Series volume, Rare Earth and Critical Elements in Ore Deposits, from the Society of Economic Geologists provides a timely review of the geology and mineralogy of a diverse group of minor elements that are now commonly termed the critical minerals or critical elements. In this context, criticality means at least two things - first, many of these commodities are vital in modern technology, particularly in clean and efficient energy generation, but also in computers and communications. The omnipresent iPhone, and all other such devices, depend on at least 20 of these little-known and rare elements. Secondly, many of these elements are equally critical in another sense, as major reserves and most production are geographically focused in countries not noted for their stability, or for political agendas closely aligned with those of western industrial consumer nations. For some elements, for example tantalum ( $\mathrm{Ta}$ ), ethical concerns have been expressed about the use of resource revenues to fuel long-lived conflicts involving human rights violations. Despite the wide perception of some of these elements as 'green' commodities, many comments have also been made concerning the environmental impacts and carbon footprints associated with their extraction and processing. In short, nothing is simple when it comes to critical minerals, and their geology is no exception. This excellent volume is a response to the need for better technical information, prompted by increased exploration to identify new sources. Much of this effort has been corporate, tempted by the prospect of strong returns on investment, but many governments also have a strong interest in reducing reliance on outside sources and their associated political-economic risks. Given this framework, it is not surprising that the United States Geological Survey (USGS) is an important supporter of this publication, which is in part a valuable outgrowth of their own work to document domestic REE resources. The fourteen chapters, each framed as an independent paper with an abstract summary and full bibliography, review known deposits and metallogenic environments largely 

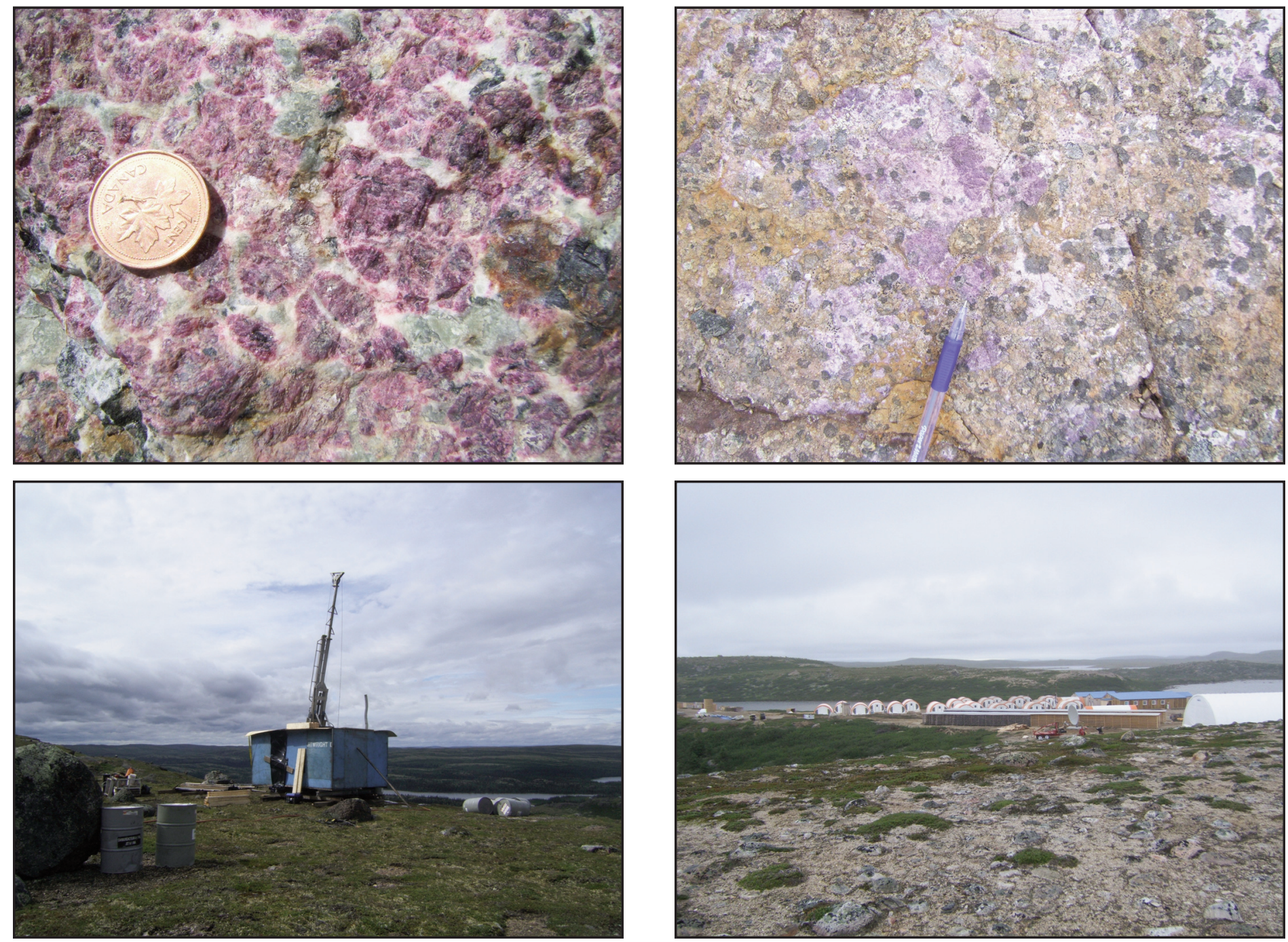

The photos above show examples of REE-enriched minerals and exploration methods in northern Canada. From the top left corner, in a clockwise order: a) The distinctive mineral eudialyte (red) from the Red Wine Mountains, Labrador. This mineral, which contains significant REE but very little $\mathrm{U}$ or Th, is of great interest as a potential source, but it has proved difficult to process. b) Magmatic-hydrothermal breccia with purple fluorite matrix from the Strange Lake REE deposit, on the Labrador-Quebec border. c) The interest in the REE led to massive exploration efforts in northern Canada, exemplified by the Quest Minerals Exploration Camp at Lac Brisson, Quebec, adjacent to the Strange Lake deposit. d) Diamond drilling in remote mountainous tundra along the Quebec-Labrador border. Photo credits: A. Kerr.

on the basis of existing data, but also incorporate information and ideas gained from recent exploration. Many papers implicitly or explicitly highlight the frustrating lack of critical facts and data - or at least the availability of such information. For example, assessment of the rhenium (Re) resources associated with copper-molybdenum deposits depends on limited and possibly unrepresentative data - in some cases only a single analysis per deposit. As Earth Scientists, we can work only with what we have, but I suspect that much more information may exist behind corporate and bureaucratic walls. The individual papers cover a wide range of topics, and they have diverse authorship, with many contributors coming from the USGS. It goes without saying that examples from Canada figure prominently in some of these papers, as we are fortunate to be endowed with significant, undeveloped resources for many of these critical minerals.

The most prominent of the so-called critical minerals are the rare-earth elements (REE), which are regular features in the popular press and no longer familiar only to chemists. These are important in many applications, from the mundane (e.g. fridge magnets) to sophisticated devices such as smart phones, flat-screen displays, wind turbines and hybrid cars. The REE were once produced in small quantities from diverse sources as primary and by-product commodities, but for almost 20 years, China has produced almost all of the global supply. Taxation policies that restricted REE exports predictably caused their prices to surge, which led to a worldwide frenzy of exploration. Like many critical minerals, the REE are 
actually very widely distributed across the globe, but this does not diminish the challenges in bringing new deposits into production, as several Canadian Junior Mining Companies have discovered. The closely similar chemical behaviour of this group of elements is well-known to geochemists - this is why we use them in research studies - and the selective production of the much rarer 'heavy' REE (gadolinium (Gd) to lutetium $(\mathrm{Lu})$ in the periodic table) is nigh impossible. About half of this volume (six full chapters and important parts of others) are related to the REE, for they truly are the poster child of critical minerals. Other elements typically associated with the $\mathrm{REE}$, such as zirconium $(\mathrm{Zr})$, niobium $(\mathrm{Nb})$, tantalum $(\mathrm{Ta})$, hafnium ( $\mathrm{Hf}$ ), beryllium (Be) and thorium (Th) also receive attention as part of this comprehensive treatment, although their sources are more diverse. Several other chapters have a different structure in that they discuss the abundance and occurrence of selected critical elements as minor components of several more familiar mineral deposit types, and the potential for by-product extraction. Some of these associations are well-known, e.g. rhenium (Re) in some porphyry-type deposits, but others are less well-documented, e.g. the enrichment of a range of minor elements in modern sea-floor massive sulphide deposits. As one would expect, granitic pegmatites - which are the very sources from which many of these unusual elements were first isolated - are given a discrete chapter of their own, and lithium brines merit similar treatment. The papers vary considerably in length and detail, but most are on the long side, with extensive tables listing known examples and features, and thorough reviews of geological and geochemical controls. Some papers extend this treatment to discussions of exploration and mineral processing methodology, but the emphasis is mostly towards geological attributes - even though the greatest obstacles to developing many deposits lie in beneficiation and refining.

I doubt that interested readers will complain about a volume that has a page for every day of the year, because these are reference pieces that will have lasting value. We would not expect them to be light reading, but many are really quite readable given their bulk. The relevance of many papers extends beyond the critical elements that might occur in a given setting, because authors also provide full descriptive and interpretive reviews of host metallogenic environments. Although the information for specific critical elements in epithermal gold deposits might in the end be fragmentary, the value of the review paper on this setting is undiminished by the inevitable questions it raises. As a neophyte editor, I was impressed with the clarity of writing and presentation and the general absence of errors. I now know only too well how hard such things are to eliminate, especially in any work that involves wide compilation of numerical data and multiple figures and maps. The consistency of presentation and figure quality is also impressive.

Most economic geologists and students of the subject will find the six chapters devoted to Rare Earth Elements (REE) the most useful and widely applicable portion of the volume. One of these papers, by Yuling Xie and others, provides a review of REE deposits in China, finally presenting descriptive material that has always been hard for geologists outside China to obtain. Two long chapters discuss the most familiar settings for REE deposits, i.e. carbonatites (by Philip Verplanck and others) and alkaline-peralkaline igneous suites (by Jarda Dostal). Both provide comprehensive information on the major deposits associated with such rocks, and do a good job of tackling the sometimes bewildering variety amongst these small-volume, aberrant igneous suites and their variably endemic mineralogy. I would not go so far as to say that my own long-standing confusion about carbonatites was eliminated through reading, but it was certainly greatly diminished! Other chapters present material that is less familiar, including an excellent descriptive and process-oriented review of socalled ion-adsorption-type REE deposits (by Kenzo Sanematsu and Yasushi Watanabe). These surficial deposits still remain the dominant source for many of the valuable heavy REE elements and, unlike other types of REE deposits, economic examples do appear to be restricted to Chinese territory. There are few easily understandable papers about the features and origins of these deposits, and this paper fills a prominent knowledge gap. Might such deposits occur elsewhere in subtropical regions underlain by granites of appropriate composition, and if they do, should Society sanction their exploitation? Interesting questions, indeed, but beyond the aims of this book. Other papers tackle placer REE deposits (by Debashish Sengupta and Bradley Van Gosen) and the important question of sedimentary phosphorite REE deposits (by Paul Emsbo and others). Amazingly, over 50,000 tonnes of REE (of which almost half represent valuable heavy REE) are mined, beneficiated and put into solution every year, but are not recovered. Evidently, phosphorite deposits could potentially meet a large portion of the world's growing demand for these elements. Interestingly, there appears to be secular variation in the abundance of REE-enriched phosphorites in the geological record, implying wider controls by oceanic chemistry, oxidation states, and perhaps global tectonic cycles. Again, this broad treatment and assessment of REE resources in this environment fills important scientific and economic needs.

Tackling the subject of pegmatites and critical elements is a very tall order, as these rocks vary enormously in composition and texture, and virtually every critical element is found in some kind of pegmatite somewhere on the Earth. The treatment by David London focuses to significant extent on the physical and chemical processes involved in this transitional magmatic- hydrothermal environment, and emphasizes some of the more valuable minerals (e.g. columbite-tantalite, spodumene, beryl, petalite and pollucite - sources of $\mathrm{Ta}, \mathrm{Li}$ and Cs) that are preferentially restricted to this environment. The remaining chapters in this volume are focused on the abundance of and potential for critical elements as by-product commodities from the processing of other types of ore deposits. These include epithermal gold deposits associated with alkaline igneous rocks (by Karen Kelley and Paul Spry emphasis on Te, PGEs, REE, F and V) and also other types of gold deposits (by Richard Goldfarb and others - emphasis on $\mathrm{Bi}, \mathrm{Hg}$, In, Sb, Se and W). Base-metal deposits receive a similar assessment, both in the modern seafloor setting (by Thomas 
Monecke and others) and in ancient sedimentary-hosted examples (by Erin Marsh and others). Associated critical elements in submarine hydrothermal systems are very diverse, including $\mathrm{Bi}$, $\mathrm{Cd}, \mathrm{Ga}, \mathrm{Ge}, \mathrm{Hg}$, In and others, with differences in the signatures of $\mathrm{Cu}$-rich and $\mathrm{Zn}-\mathrm{Pb}$-rich systems, and also interesting contrasts with ancient examples preserved as VMS deposits. Some of these same elements are also present in sedimenthosted sulphide deposits of various types, although available data are limited. The final two papers of this type assess critical-element abundances in sandstone-hosted uranium deposits (by George Breit - emphasis on Mo, Re, Sc, REE, V and Se) and the well-known association between Re enrichment and porphyry copper-molybdenum deposits (by David John and Ryan Taylor). Although both deposit types constitute important economic resources in the western United States, it seems that data on minor element geochemistry for such settings remains scattered and of variable quality. The final contribution on lithium-rich brines (by Lee Ann Munk and others) is another example of a much-needed global review of a topic for which previous syntheses are nonexistent or hard to obtain. These represent one of the lowest-cost options for meeting growing demand for this commodity, linked to its widespread use in the power sources that fuel our mobile technology. This subject is also one of major relevance in the western United States, where known and potential resources exist.

This volume is definitely not a mainstream text book with a wide potential audience, but for those with a specific interest in these diverse commodities, or in educating students about the sheer breadth and scope of economic geology, I believe that it will prove invaluable. It provides not only an up-to-date summary of these important deposit types, but also highlights the gaps in knowledge that need to be filled in the interests of greater understanding and more successful exploration. It also makes a good case for systematic geoscience of the kind completed by the USGS and its sister organizations - without this public input, much of the data here would probably never have been acquired, or collated in such seamless form. The Society of Economic Geologists is to be congratulated for its efforts in bringing this project to fruition, and the editors are to be congratulated for what must at times have seemed a hard and endless task. The authors also deserve congratulations, for some of these papers represent enormous compilation and interpretation efforts. It is hard to predict exactly which of the critical elements will remain critical in the light of increased exploration and other political or economic developments, but one thing is for sure - this compilation will remain a critical source of knowledge, and should disseminate that knowledge well. For anyone with a broad interest in economic geology, it is a rare and valuable commodity in its own right.

\section{ACKNOWLEDGEMENT}

I would like to thank Steve Amor for his comments and suggestions on the initial version of this book review. 